\title{
Elimination of histamine liberator (acetaldehyde) by L-cysteine in prevention of migraine attacks: Randomized controlled trial with a medical device (Acetium ${ }^{\circledR}$ Capsules)
}

Mikko Kallela, Markku Nissilä, Petra Keski-Säntti, Marja-Liisa Sumelahti, Mikko Kärppä, Matti Ilmavirta, Markus Färkkilä, Lea Paloheimo, Minna Mäki, Kari Syrjänen* and Osmo Suovaniemi

Department of Clinical Research, Biohit Oyj (Helsinki), Finland

\begin{abstract}
Background \& Study Design: Endorsements from migraine patients testifying that L-cysteine effectively prevented their headache attacks, prompted us to design a double-blind, randomized placebo-controlled, multi-centre trial (with 218 patients) comparing Acetium ${ }^{\circledR}$ capsules $(100 \mathrm{mg}$ L-cysteine, inactivating acetaldehyde in the stomach) and placebo in prevention of migraine attacks during a 3-month trial period.

Methods: Migraine diaries were evaluated at monthly intervals for study compliance. The primary study endpoint was reduction in the number of migraine days (NMD), assessed at 4 cut-offs: $\geq 50 \%, \geq 30 \%, \geq 25 \%$ and $\geq 20 \%$.

Results: Altogether, 146 patients had completed the study per protocol. Using the most stringent cut-off $(\geq 50 \%)$ for reduction of NMD, the success rate in the Acetium ${ }^{\circledR}$ arm was $26.0 \%$ and in the placebo arm 25.4\%; OR=1.027 (95\%CI 0.589-1.79) ( $\left.\mathrm{p}=\mathrm{NS}\right)$. Among the patients with a potential acetaldehyde-associated trigger (alcohol, smoking, dietary), Acetium ${ }^{\circledR}$ was up to $50 \%$ more effective than placebo in NMD reduction by various cut-offs, with the highest OR=1.569 (95\%CI $0.743-3.312)$
\end{abstract}

Conclusions: Although Acetium ${ }^{\circledR}$ was not more effective than placebo in reducing the NMD in the global analysis, certain sub-groups might benefit from Acetium ${ }^{\circledR}$ intervention considerably more than migraine patients collectively.

\section{Introduction}

Prophylactic treatment is an important part of the total management of migraine patients, having twofold goals: i) to reduce the frequency, painfulness, and/or duration of migraines, and ii) to increase the effectiveness of abortive therapy [1-4]. According to the EHF (European Headache Federation) guidelines, the following are listed as drugs with good evidence of efficacy: beta-adrenergic blockers, topiramate, flunarizine, sodium valproate and amitriptyline [5]. In addition to a lengthy list of lower-efficacy drugs, most anti-depressants are listed as "clinically efficacious based on consensus of experience" without scientific support [5]. The latest therapeutic innovations are based on monoclonal antibodies (e.g. galcanezumab), blocking the effect of calcitonin gene-related peptide (CGRP) [6].

Migraine patients started giving testimonials to Biohit Oyj (Helsinki, Finland) reporting that the company's medical device, Acetium ${ }^{\circ}$ capsule $(100 \mathrm{mg}$ L-cysteine, used for inactivation of acetaldehyde in the stomach) [7], had almost aborted their migraine attacks, inducing complete remission for up to years. Our novel hypothesis to explain these anti-migraine effects includes the following components: i) nitric oxide (NO) is the final trigger of migraine attack; ii) histamine induces NO synthase; iii) histamine is synthesized in tissue mast cells and basophils; iv) histamine is liberated from mast cells by acetaldehyde $[8,9]$; and $v$ ) acetaldehyde in the saliva and stomach is inactivated by L-cysteine [7].

Our RCT tested this novel hypothesis that daily use of Acetium ${ }^{\circledR}$ capsules ( $100 \mathrm{mg}$ b.i.d.) is an effective means in prevention of migraine attacks.

\section{Material and methods}

The present study strictly followed the guidelines published by the International Headache Society Clinical Trials Subcommittee [10]. This double-blind, randomized placebo-controlled multi-centre trial compared Acetium capsules (100mg L-cysteine, twice a day) with placebo in prevention of migraine attacks during a 3-month trial period. The study was approved by the Ethics Committee of Helsinki University Hospital (HUS). Between 2015-2018, a cohort of 218 consented women and men suffering from migraine with or without aura, were enrolled by 6 clinics in Finland and 2 clinics in Estonia. The eligible patients with confirmed (ICHD-3 beta) diagnosis are those who should: i) have the attack frequency of 2-8 days per month, ii) have had migraine for at least 1 year, iii) have the onset of their migraine before 50 years of age, iv) be between 18 and 65 years of age, and v) have a minimum or no co-morbidity [10].

${ }^{*}$ Correspondence to: Syrjänen $\mathrm{K}$, prof. MD, PhD, FIAC. SMW Consultants Ltd, Kylliäisentie 9, FI-21620 Kuusisto, Finland, Tel: +358-40-5566810; E-mail: kasyrja@netti.fi

Key words: migraine, attacks, prevention, L-cysteine, acetaldehyde, histamine liberation, acetaldehyde elimination, randomized controlled trial (RCT), doubleblind, placebo-controlled, number of migraine days (NMD), reduction of NMD, sub-group analysis, triggers, alcohol, smoking, dietary

Received: July 08, 2021; Accepted: July 23, 2021; Published: July 26, 2021 
Kallela M (2021) Elimination of histamine liberator (acetaldehyde) by L-cysteine in prevention of migraine attacks: Randomized controlled trial with a medical device (Acetium ${ }^{\circledR}$ Capsules)

After randomization, the treatment period in both arms was 3 months, followed by a 1 -month post-trial observation period. The headache diary was the main tool used to monitor the efficacy of the test preparations at 1-month intervals, including efficacy and safety [10]. This study ( $\mathrm{n}=100$ per study arm) was estimated to be adequately powered to detect a true difference in attack frequency between 4 attacks/month in the placebo and 2.4 attacks/month in the Acetium arm. The primary study endpoint was reduction of the number of migraine days (NMD) per month, tested using 4 different cut-offs: $\geq 50 \%, \geq 30 \%, \geq 25 \%$ and $\geq 20 \%$ reduction [10]. In statistical analysis, SPSS statistics (SPSS Statistics 27.0.1.0; IBM, Armonk, NY, USA) was used to analyse the data, using conventional techniques

\section{Results}

Of the originally enrolled 218 study subjects, only 146 patients had completed the study per protocol (PP) and considered eligible for the final analyses. The 72 drop-outs were due to incomplete or inconsistent data in the diaries. The primary endpoint results are presented in Table 1. In the global analysis, no statistical difference between the two study arms was detected using $\geq 50 \%, \geq 30 \%, \geq 25 \%$ and $\geq 20 \%$ cutoffs in reduction of NMD. Using the most stringent cut-off $(\geq 50 \%)$, the success rate in the Acetium ${ }^{\circ}$ arm was $26.0 \%$ and in the placebo arm 25.4\%; OR=1.027 (95\%CI 0.589-1.79)( $\mathrm{p}=\mathrm{NS})$. Similarly, the absolute mean NMD reduction did not differ significantly between the Acetium ${ }^{\circ}$ and placebo arms: 1.14 days and 0.56 days, respectively.
Sub-group analyses for NMD reduction were completed for patients who reported potential acetaldehyde-associated triggers of their migraine: i) alcohol, ii) cigarette smoking, iii) dietary (Table 2). Among alcohol-triggers, Acetium ${ }^{\star}$ was $>10 \%$ more effective than placebo in reducing NMD by $\geq 20 \%$ cut-off; $61.8 \%$ vs. $50.0 \%$ ( $\mathrm{p}=0.464$ ). Among the smoking triggers, $66.7 \%(\mathrm{n}=2)$ achieved $\geq 50 \%$ reduction in NMD with Acetium ${ }^{\star}$ as compared with $0 \%$ for those using placebo. Similarly, $>20 \%$ more subjects received $\geq 20 \%$ reduction in NMD among those who reported a dietary trigger.

\section{Discussion}

Acetium $^{\odot}$ capsule (a medical device) was originally introduced for elimination of carcinogenic acetaldehyde in the stomach [7] Given that acetaldehyde effectively liberates histamine from the mast cells at different body sites $[8,9]$, it was reasoned that by eliminating acetaldehyde in the stomach, L-cysteine could block (or reduce below the threshold levels) histamine liberation from the tissue mast cells. This in turn could result in arresting the multitude of histamine functions $[8,9]$, including swelling and dilatation of cerebral blood vessels.

Due to the complexity of migraine pathophysiology, it is unlikely that any single drug would be a perfect remedy to all patients [1-6]. When the present cohort was analysed in total, Acetium ${ }^{\circ}$ capsules were not more effective than placebo in reducing NMD (Table 1). Despite the positive testimonials from a number of migraine patients, these data suggest that Acetium ${ }^{\circ}$ capsule is not effective in prevention of any type of migraine. Given the mechanism of Acetium ${ }^{\bullet}$ action (i.e.,

Table 1. The effect of Acetium ${ }^{\circledR}$ Capsule and placebo in reduction of the number of migraine days (NMD)

\begin{tabular}{|c|c|c|c|c|c|c|c|c|}
\hline \multirow[t]{3}{*}{ Study Arm } & \multicolumn{8}{|c|}{ Reduction in the Number of Migraine Days (NMD) by: } \\
\hline & \multicolumn{2}{|c|}{$\geq \mathbf{5 0} \%$} & \multicolumn{2}{|c|}{$\geq \mathbf{3 0} \%$} & \multicolumn{2}{|c|}{$\geq \mathbf{2 5 \%}$} & \multicolumn{2}{|c|}{$\geq \mathbf{2 0} \%$} \\
\hline & No. & Per Cent & No & Per Cent & No & Per Cent & No & Per Cent \\
\hline 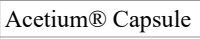 & 19 & 26.0 & 30 & 41.1 & 38 & 52.1 & 41 & 56.2 \\
\hline Placebo & 18 & 25.4 & 27 & 38.0 & 32 & 45.1 & 37 & 52.1 \\
\hline OR $(95 \% \mathrm{CI})$ & 1.027 & $89-1.790)$ & 1.08 & 21-1.619) & 1.15 & 24-1.620) & 1.078 & $97-1.457)$ \\
\hline Significance & & 926 & & 736 & & 411 & & 738 \\
\hline
\end{tabular}

Table 2. The effect of Acetium ${ }^{\circledR}$ Capsule and placebo in reduction of the number of migraine days (NMD) in specific sub-groups of patients

\begin{tabular}{|c|c|c|c|c|}
\hline \multirow{3}{*}{ Study Arm / Sub-Groups } & \multicolumn{4}{|c|}{ Reduction in the Number of Migraine Days (NMD) by: } \\
\hline & $\geq \mathbf{5 0 \%}$ & $\geq \mathbf{3 0} \%$ & $\geq \mathbf{2 5} \%$ & $\geq \mathbf{2 0} \%$ \\
\hline & Per Cent & Per Cent & Per Cent & Per Cent \\
\hline \multicolumn{5}{|l|}{ Alcohol Trigger: } \\
\hline Acetium ${ }^{\circledR}$ Capsule & 23.5 & 41.2 & 52.9 & 61.8 \\
\hline Placebo & 26.5 & 44.1 & 47.1 & 50.0 \\
\hline OR $(95 \% \mathrm{CI})$ & $0.889(0.389-2.029)$ & $0.933(0.538-1.621)$ & $1.125(0.698-1.813)$ & $1.235(0.805-1.895)$ \\
\hline Significance & $\mathrm{p}=1.000$ & $\mathrm{p}=1.000$ & $\mathrm{p}=0.809$ & $\mathrm{p}=0.464$ \\
\hline \multicolumn{5}{|l|}{ Smoking Trigger: } \\
\hline Acetium ${ }^{\circledR}$ Capsule & 66.7 & 66.7 & 100.0 & 100.0 \\
\hline Placebo & 0.0 & 50.0 & 50.0 & 50.0 \\
\hline OR $(95 \% \mathrm{CI})$ & $\mathrm{NC}$ & $1.333(0.269-6.606)$ & $\mathrm{NC}$ & $\mathrm{NC}$ \\
\hline Significance & $\mathrm{p}=0.400$ & $\mathrm{p}=1.000$ & $\mathrm{p}=0.400$ & $\mathrm{p}=0.400$ \\
\hline \multicolumn{5}{|l|}{ Dietary Trigger: } \\
\hline Acetium ${ }^{\circledR}$ Capsule & 29.4 & 35.3 & 52.9 & 58.8 \\
\hline Placebo & 25.0 & 31.3 & 37.5 & 37.5 \\
\hline OR $(95 \% \mathrm{CI})$ & $1.176(0.382-3.619)$ & $1.129(0.438-2.982)$ & $1.412(0.650-3.065)$ & $1.569(0.743-3.312)$ \\
\hline Significance & $\mathrm{p}=1.000$ & $\mathrm{p}=1.000$ & $\mathrm{p}=0.491$ & $\mathrm{p}=0.303$ \\
\hline \multicolumn{5}{|l|}{ Any Trigger (ASD): } \\
\hline 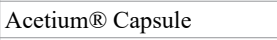 & 25.6 & 41.9 & 53.5 & 60.5 \\
\hline Placebo & 27.9 & 41.9 & 46.5 & 48.8 \\
\hline OR $(95 \% \mathrm{CI})$ & $0.917(0.455-1.847)$ & $1.000(0.608-1.646)$ & $1.150(0.752-1.759)$ & $1.238(0.838-1.828)$ \\
\hline Significance & $\mathrm{p}=1.000$ & $\mathrm{p}=1.000$ & $\mathrm{p}=0.667$ & $\mathrm{p}=0.386$ \\
\hline
\end{tabular}

$\mathrm{NC}$, not calculable; ASD, alcohol-, smoking-, dietary trigger 
elimination of alcohol-derived acetaldehyde), this may turn attention to special sub-groups of patients who report a potential acetaldehydeassociated trigger of their migraine atacks.

When the efficacy analyses were repeated in patients who report alcohol, smoking or dietary trigger (or in any combination)(Table 2), Acetium was $10-20 \%$ (sometimes $50-66.7 \%$ ) more effective than placebo in NMD reduction, but none of the differences reached statistical significance. These calculations are limited by the very small size of each strata, which is the most serious limitation of this study. Another limitation is the failure to test different dosages of Acetium capsules, e.g. 2 capsules $x 3$, connected with meals [7]. When the highest $\mathrm{OR}=1.569$ (95\%CI $0.743-3.312$ )(i.e., $\geq 20 \%$ NMD reduction among dietary triggers)(Table 2) is considered, an adequate statistical power would be reached with 86 subjects in both study arms.

\section{Conclusion}

- This RCT testing the efficacy of Acetium ${ }^{\circ}$ capsule in migraine prevention, gave negative results in the global analysis covering all migraine patients.

- However, an adequately powered cohort is warrented to demonstrate the efficacy of Acetium ${ }^{\otimes}$ in prophylactic treatment of migraine patients who report potentially acetaldehyde-associated external triggers of their attack.

\section{Declarations}

\section{Funding}

This study was funded in full by Biohit Oyj, covering the costs of the design of the study and its execution in the collaborating centres, including collection, analysis, and interpretation of the data as well as the consultant's cost (KS) due to writing the manuscript.

\section{Conflicts of interest/Competing interests}

MK, MN, PKS, MLS, MK, MI, MF are all neurologists, who declare that they have no competing interests. LP and KS are retired directors of Biohit Oyj (the proprietary of the Acetium trade mark). MM is the acting director of $\mathrm{R} \& \mathrm{D}$, Biohit Oyj; OS is the Chairman of the Board of Directors, Biohit Oyj (Helsinki, Finland).

\section{Ethics approval}

The study was approved by the Committee of Medical Research Ethics, Helsinki University Hospital (HUS). The original approval (299/13/03/01/2013) and two amendments 30.04.2014 and 22.02.2017.

\section{Consent to participate}

All study subjects signed a written consent to participate before enrolled in the study. This was requested by the Ethical Approval.

\section{Consent for publication}

All authors have read the final manuscript and given their approval for publication.

\section{Availability of data and material (data transparency)}

The datasets during and/or analysed during the current study available from the corresponding author on reasonable request. The datasets generated during and/or analysed during the current study are not publicly available due [confidentiality reasons] but are available from the corresponding author on reasonable request.

\section{Code availability (software application or custom code)}

Not applicable

\section{Authors' contributions}

MK, MN, PKS, MLS, MK, MI, MF are all specialist neurologists, who contributed to the design of this study. They also completed the entire clinical part of this trial in their respective clinics. LP and KS as former directors of Biohit Oyj had a key role in designing the study. $\mathrm{MM}$ as the current director of $\mathrm{R} \& \mathrm{D}$, Biohit Oyj has done the same, and started her involvement at the stage when the trial was already ongoing; OS is the Chairman of the Board of Directors, Biohit Oyj has had the overall control of the study until its completion. MK performed the clinical validation of the collected data as a neurology specialist and PI of the study. KS performed the analysis of the data and was the major contributor in writing the manuscript. All authors have read and approved the final manuscript.

\section{References}

1. Bartleson JD, Cutrer FM (2020) Migraine update: Diagnosis and treatment. Minn Med 93: 36-41. [Crossref]

2. Negro A, Rocchietti-March M, Fiorillo M, Martelletti P (2011) Chronic migraine: current concepts and ongoing treatments. Eur Rev Med Pharmacol Sci 15: 1401-1420. [Crossref]

3. Modi S, Lowder D (2006) Medications for migraine prophylaxis. Am Fam Phys 73 $72-78$.

4. Silberstein S, Tfelt-Hansen P, Dodick DW, Limmroth V, Lipton RB, et al. (2008) Guidelines for controlled trials of prophylactic treatment of chronic migraine in adults. Cephalalgia 28: 484-495. [Crossref]

5. Steiner TJ, Paemeleire K, Jensen R, Valade D, Savi L, et al. (2007) EGM on behalf of the European Headache Federation. European principles of management of common headache disorders in primary care. J Headache Pain 8: S3-S21. [Crossref]

6. Sacco S, Bendtsen L, Ashina, M, Reuter U, Terwindt G, et al. (2019) European headache federation guideline on the use of monoclonal antibodies acting on the calcitonin gene related peptide or its receptor for migraine prevention. $J$ Headache Pain 20: 6. [Crossref]

7. https://www.acetium.com/en/stomach-problems/acetium-capsule/

8. Koivisto T, Kaihovaara P, Salaspuro M (1999) Acetaldehyde induces histamine release from purified rat peritoneal mast cells. Life Sci 64: 183-190. [Crossref]

9. Kawano T, Matsuse H, Kondo Y, Machida I, Saeki S, et al. (2004) Acetaldehyde induces histamine release from human airway mast cells to cause bronchoconstriction. Int Arch Allerg Immunol 134: 233-239. [Crossref]

10. Tfelt-Hansen P, Pascual J, Ramadan N, Dahlo C, D'Amico D, et al. (2012) Guidelines for controlled trials of drugs in migraine: Third edition. A guide for investigators. Cephalalgia 32: 6-38. [Crossref]

Copyright: (C2021 Kallela M. This is an open-access article distributed under the terms of the Creative Commons Attribution License, which permits unrestricted use, distribution, and reproduction in any medium, provided the original author and source are credited. 